\title{
Research on the Mobile Terminal APP Based on Educational Administration System
}

\author{
Shanjing Wang ${ }^{1, a}$, Hongyu $\mathrm{Li}^{1, \mathrm{~b}}$, Liming Wang ${ }^{1, \mathrm{c}}$ \\ ${ }^{1}$ No.77, Hanlin Road, Economic and Technological Development District, Jilin prov. \\ ajlnyedu@163.com, barm9linux@163.com, '80661664@qq.com \\ * The Corresponding author
}

Keywords: Mobile terminal; Medical education; The teaching reform

\begin{abstract}
With the development of the mobile terminal manufacturing level, and mobile terminal speed faster and faster in past years, the price is more and lower; Finally, The Internet by mobile phone and other devices connected to each one of us. Network evaluation system based on PC, in the past, needs for mobile terminals, overcome based on desktop, notebook assessment system of space limitations, mobile terminals make more real-time evaluation of data acquisition, the density is higher, even can be accurate to every class teaching effect evaluation. Long time and high density of appraisal data through the cloud, big data representation, can be more comprehensive reflect the teachers Teaching level and curriculum knowledge structure is reasonable.
\end{abstract}

\section{Introduction}

In China, The mainland's top university rankings of colleges and universities at home and abroad in recent years, the cognition to the educational administration and teaching evaluation system, most did not implement, Some schools to teacher's evaluation is often conducted in students in the classroom, to evaluate the teacher in class, use the rest of the class time by the school management personnel sent to the student teacher evaluation, The evaluation approach and how would it be possible to get a real, objective evaluation.

Of these ills not in addition to, But not to establish a perfect supervision mechanism of management, none of the integration of teaching evaluation and management system, is a great limit to the development of undergraduates. Don't make undergraduate education "type education" factory mass production, still need to deeply dig out the root cause of colleges and universities, for lesions, suit the remedy to the case.

\section{The Paper Mainly Purpose and Significance}

(1)The application of mobile terminal Android APP development.

(2)Database, data management mechanism and algorithm implementation on the Android APP.

(3)APP and gathering information database communication and the evaluation of the PC software development.

\section{The Working Principle of this Software}

According to the actual application value of the project survey, in the process of practical projects, often face the biggest problem is how to integrate each of database data, that is to say, Because of the difference of the allocation of resources, some of the college educational administration website database is their development and construction of school computer major, this is very convenient to provide database access interface, however, the reality is that different school construction site database interface is different, currently on the market two of the most popular database interface ODBC and JDBC, if the integration of heterogeneous database using ODBC database interface, ODBC is based on SQL (Structured Query Language), integrate SQL data within the database data types, on the basis of 13 kinds of SQL data types, read and display integration of data in the APP, is a very complex task. 


\section{The Introduction of this APP}

APP generic interface to reserve network, sending and receiving data from the database and the data sent to the database, the network interface through a standard communication protocol, external data reception can receive $2 \mathrm{~g}, 3 \mathrm{~g}, 4 \mathrm{~g}$ and WIFI data link, after data collection via FTP transmitted to the target server host, in the form of database, the data summed up by the database and displayed on a PC software.

\section{The App Function Description}

Build a complete system for the performance of packaged software system testing, including database data integration, mobile devices, Android APP application software and database communication, We Chat APP development plan design.

\section{Academic Web Site Management System's Database Development}

According to the actual application value of the project survey, in the process of practical projects, often face the biggest problem is how to integrate each of database data, that is to say, because of the difference of the allocation of resources, some of the college educational administration website database is their development and construction of school computer major, this is very convenient to provide database access interface, however, the reality is that different school construction site database interface is different, currently on the market two of the most popular database interface ODBC and JDBC, if the integration of heterogeneous database using ODBC database interface, ODBC is based on SQL (Structured Query Language), integrate SQL data within the database data types, on the basis of 13 kinds of SQL data types, read and display integration of data in the APP, is a very complex task.

\section{The Implementation of Evaluation System}

The collection includes background management personnel information management and access control two function modules. Although access control module is not an independent existence, but it runs through the whole operation in the process. Student information system management personnel management module takes privilege Rights can be normal use. Permissions function module to determine the user role by system management personnel, with appraisal qualification of the students. as shown in fig. 4.1. 


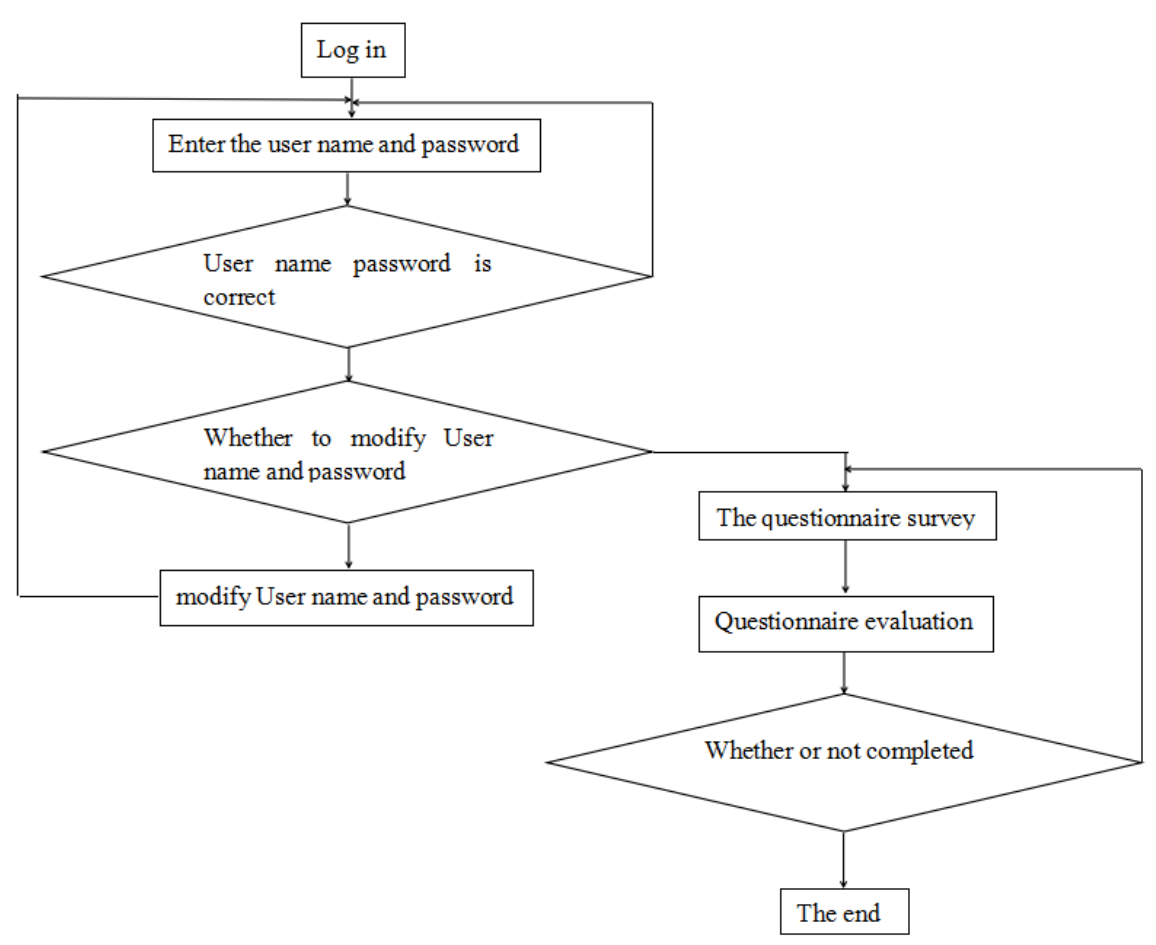

Figure 4.1. Students online questionnaire evaluation flow chart

\section{Student Questionnaire Management Module}

Student management module includes questionnaire, questions, questions option three tables. With Evaluation (vote) of the vote in administrative authority of the administrator can add, delete, fix it Change, all the voting form to provide the evaluation index of teaching quality security documents shall prevail. World Graphic design with list to manage data, list all the questionnaire, and questionnaire, issues, and Problems associated options, when choosing questionnaire automatically relevant problems and options to columns Table form for display.

\section{Student Management Module}

Student management module includes the most highly relational tables. Has the student administrative privileges Users can manage the students voted to set. Open interface provides questionnaire options and vote Start time and end time choice, by reading the task list, the commencement of the automatic configuration is needed To evaluate which course and which the relationship between a teacher and click the add button to automatically set after evaluation Coefficient according to the evaluation of a relational table.

\section{Student Management Module}

All the current semester after the polls close, the system for evaluating the grade students into relational tables Decryption and statistics, which has the vote statistics authority system users can to the current number According to export, which is convenient for analysis. Interface with list: lists the current teaching of the term Master data, curriculum and evaluation score, in addition to the average of maximum and minimum of each $10 \%$ of the data, in order to guarantee the fairness and rationality of evaluation data. Provide the Excel document Export function, convenient for data archiving and handling. In addition, also provides the teacher evaluation Fine data analysis chart, histogram, pie charts and the linear graph form to display, System start up interface as shown Fig. 2.1 . 


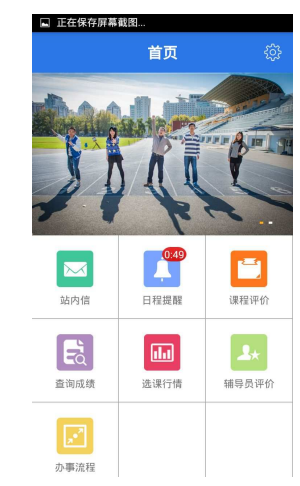

Figure 2.1 The APP homepage

\section{Conclusion}

Student evaluation system provides users with rich operation function, realize the appraisal For automation, thus greatly reduce the intensity of the work of student management, reduce A lot of manual operation may cause error, improve the student management work Efficiency, promotes the student information construction. And when will evaluation information for head teachers, related departments and schools. At the same time, the security and reliability of information in the preservation and transmission has been more effective protection.

\section{Acknowledgements}

Project Source:

JILin Agriculture Science And Technology College Innovation item No.116012016001.

Corresponding author: Zheng Liang.

No.77, Hanlin Road, Economic and Technological Development District, Jilin prov.

\section{References}

[1] Ackerman, D, Gross, B. L. \& Vigneron, F. 2009 .Peer observation reports and student evaluations of teaching: Who are the experts ? Alberta Journal of Education Research. (55). $18 \sim 39$.

[2] Arreola R A. 1993.Developing a comprehensive faculty evaluation system. Bolton. MA: Anker Pulishing Company. (11). 8.

[3] Beran, T.N. \& Rokosh,J. L.2009b.Instructors' perspectives on the utility of student ratings of instruction. Instructional Science. (37).171 184.

[4] Beecham, R.2009.Teaching quality and student satisfaction: Nexus or simulacrum? London Review of Education.(7).135 146.

[5] E A Arubayi. Improvement of Instruction and Teacher Effectiveness.1987.Are Student Ratings Reliable and Valid? High Education: 138.

[6] Franklin, J. 2001. Interpreting the numbers: Using a narrative to help others read student evaluations of your teaching accurately. New Directions for Teaching and Learning.(87). 85 100.

[7] Johnson, R.(2000). The authority of the student evaluation questionnaire. Teaching in Higher Education.(5).419 434.

[8] Kulik, J.A. 2001. Student ratings: Validity, utility and controversy. New Directions for Institutional Research.(27). 9 25.

[1] Sitzman, K. 2010. Student-preferred caring behaviors for online nursing education. Nursing Education Perspective.(31).171 178. 
[2] Wolf, Z.R., Bender, P. J.,Beitz, J.M., Wieland,D.M.\&Vito.K.2004.Strengths and weaknesses of faculty teaching performance reported by undergraduate and graduate nursing students: A descriptive study. Journal of Professional Nursing.(20).118 122. 